\title{
Prediction of Solid-liquid Interfacial Energy of Steel during Solidification and Control of Dendrite Arm Spacing
}

\author{
Hideo MIZUKAMI, ${ }^{1 *}$ Koutarou HAYASHI, ${ }^{21}$ Mitsuhiro NUMATA ${ }^{1)}$ and Akihiro YAMANAKA ${ }^{11}$ \\ 1) Technical Research \& Development Bureau, Nippon Steel \& Sumitomo Metal Corporation, 16-1 Sunayama, Kamisu, Ibaraki-

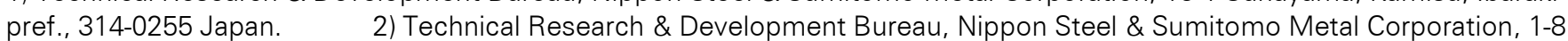 \\ Fuso-cho, Amagasaki, Hyogo-pref., 660-0891 Japan.
}

(Received on July 30, 2012; accepted on August 23, 2012; originally published in Tetsu-to-Hagané, Vol. 97, 2011, No. 9, pp. 457-466)

\begin{abstract}
Solid-liquid interfacial energy of steel during solidification was measured predicted from the both experimental techniques of unidirectional solidification and thermal analysis applying the dendrite growth model and heterogeneous nucleation model. Solid-liquid interfacial energy changed depending on primary phase during solidification, i.e., that of primary $\delta$ phase was larger than that of $\gamma$ phase. When the primary phase was the same, solid-liquid interfacial energy increased with increasing $C$ content. Primary dendrite arm spacing changed depending on solid-liquid interfacial energy. A trace amount of Bi which had the effect of a decrease in the solid-liquid interfacial energy of steel during solidification decreased primary and secondary dendrite arm spacing, significantly.
\end{abstract}

KEY WORDS: solidification; solid-liquid interfacial energy; dendrite arm spacing; undercooling; bismuth.

\section{Introduction}

Demand of high performance products of carbon steel is increasing recently. Some properties of final product are occasionally affected by the quality of continuously cast slabs. Therefore, the refinement of solidification microstructure becomes important, especially to improve tensile strength and toughness. A novel technology to control solidification structure has to be developed to improve the internal quality for extremely thick plates products which are difficult to meet the standard of reduction ratio. ${ }^{1-3)}$ With this technology, it is expected to improve the improvement of surface quality for direct rolling products which have coarsen $\gamma$ grains $^{1-3)}$ and to disperse fine inclusions which are precipitated with microsegregation during solidification. To solve these development subjects, it is necessary to refine the microstructure and reduce microsegregation during solidification. The study to control $^{4)}$ solidification microstructure in slabs therefore becomes urgent.

A number of studies have been carried out on how the surface and the internal defects generate in continuously cast slabs. Some studies have been done on thermo-mechanical control process and on suppression of coarsening of grain with fine inclusions precipitated. However, technology to control solidification microstructure of continuously cast slabs have not been established. It is necessary to understand the dendritic growth mechanism for control of the solidification microstructure. However, the growth of dendrite is

* Corresponding author: E-mail: mizukami.4m7.hideo@jp.nssmc.com DOI: http://dx.doi.org/10.2355/isijinternational.52.2235 determined by the cooling condition in both the mold and the secondary cooling region, and then is restricted by the equipment of continuous casting machine. Therefore, it is difficult to change cooling conditions in actual process. Thus, establishment of a new control technology has been expected. $^{5-15)}$

By the way, it becomes possible to quantitatively predict dendritic growth by advancing of the dendritic growth model $^{16-18)}$ and the phase field model. ${ }^{19-21)}$ However, to accurately simulate the dendritic growth, accurate physical properties are required. The interfacial energy between solid and liquid ${ }^{22-25)}$ in molten steel has not been evaluated sufficiently due to difficulty to measure this value at high temperatures. In the present paper, based on the dendrite growth model, ${ }^{17)}$ the solid-liquid interface energy corresponding to a primary phase was estimated from the measurement results of primary dendrite arm spacing in the samples which were given by the unidirectional solidification experiment. Furthermore, to verify the value, the solid-liquid interfacial energy was determined from the measurement results of undercooling during solidification. For the refinement of dendritic microstructure which was the final purpose in this paper, a trace amount of surface acting element was added to molten steel samples to examine its effect.

\section{Experimental Procedures}

\subsection{Unidirectional Solidification}

To evaluate the solid-liquid interfacial energy during solidification based on the dendrite growth model, it is necessary to measure the primary dendrite arm spacing which 
grows under steady state condition defined by both the temperature gradient and the growth rate. Because the experimental method by unidirectional solidification ${ }^{26-36)}$ is suitable for this purpose, the solid-liquid interfacial energy which corresponded to a primary phase was determined by this technique.

As shown in Fig. 1(a), the sample was melted and solidified unidirectionally under argon gas atmosphere in the vacuum vessel. Heating element made of carbon sleeve was heated up by the high frequency induction coil to indirectly heat up the specimen. A cylindrical sample of $1.0 \times 10^{-2} \mathrm{~m}$ in outside diameter and $2.0 \times 10^{-1} \mathrm{~m}$ in length was set up in the pipe made of alumina of $1.5 \times 10^{-2} \mathrm{~m}$ in outside diameter, $1.1 \times 10^{-2} \mathrm{~m}$ in internal diameter and $2.5 \times 10^{-1} \mathrm{~m}$ in length. The top edge of alumina tube was fixed with the chuck which was able to be opened and shut. After moving the heating unit by $4.0 \times 10^{-2} \mathrm{~m}$ with a velocity of $6.7 \times 10^{-5} \mathrm{~ms}^{-1}$, both the shutter at the bottom of vacuum vessel and the chucks which fixed the sample and alumina tube were opened at the same time. Subsequently, the solidifying sample was dropped in the water bath to quench it.

After moving the heating unit by $2.5 \times 10^{-2} \mathrm{~m}$, a B type thermocouple of $3.0 \times 10^{-4} \mathrm{~m}$ in outside diameter which was set in the protective alumina tube of $3.0 \times 10^{-3} \mathrm{~m}$ in outside diameter and $2.0 \times 10^{-3} \mathrm{~m}$ in inside diameter was immersed in molten steel sample from the above to measure the temperature at the solid-liquid interface to $5.0 \times 10^{-3} \mathrm{~m}$ at intervals of $1.0 \times 10^{-3} \mathrm{~m}$. From these results, the temperature

(a)

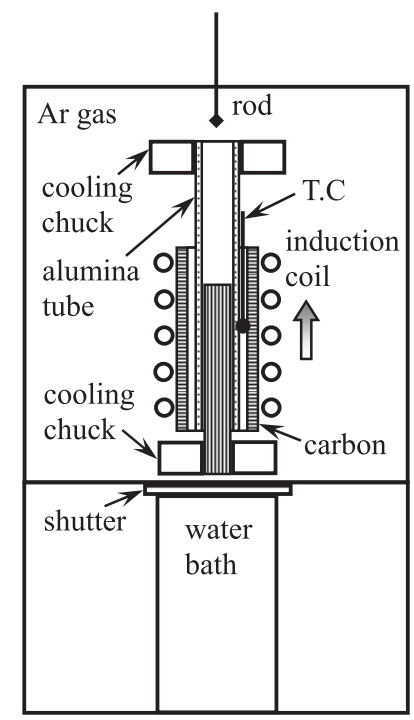

(b)

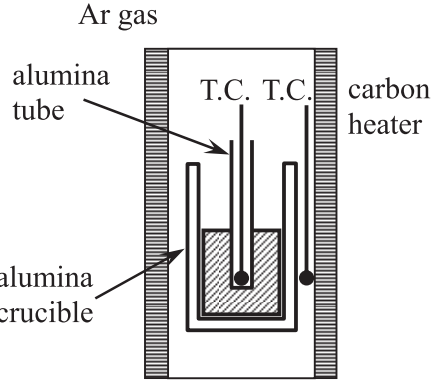

Fig. 1. Schematic diagram of experimental apparatus for (a) unidirectional solidification and (b) measurement of undercooling during solidification. gradient was decided to $8.0 \times 10^{3} \mathrm{Km}^{-1}$.

The position of solid-liquid interface was specified from the longitudinal cross section of microstructure while the dendrite arm spacing was measured on the transverse cross section below this interface of $5.0 \times 10^{-4} \mathrm{~m}$. As dendrites can be assumed to be arranged squarely, the primary dendrite arm spacing is calculated by using the following equation ${ }^{36)}$ based on the number of dendrites per unit area. To observe the dendritic microstructure, the specimen was immersed in the saturated picric acid solution heated to $353 \mathrm{~K}$ for about $60 \mathrm{~s}$.

$$
\lambda_{1}=\sqrt{\frac{A}{n}}
$$

where, $\lambda_{1}$ : the primary dendrite arm spacing $(\mathrm{m}), A$ : observed area $\left(\mathrm{m}^{2}\right), \mathrm{n}$ : number of dendrites.

Table 1 shows the chemical composition of the steel samples. The ingots were made in a $30 \mathrm{~kg}$ vacuum furnace followed by forged. The samples were machined to the round bars of $1.0 \times 10^{-2} \mathrm{~m}$ in diameter and $1.5 \times 10^{-1} \mathrm{~m}$ in length. As a primary phase became $\delta$ phase or $\gamma$ phase, the C concentration of the sample has been changed. Moreover, to evaluate the influence of an interfacial active element on the primary dendrite arm spacing, Bi was wrapped with pure iron foil was added into the molten steel.

\subsection{Thermal Analysis}

The solid-liquid interfacial energy can be evaluated from the measurement results of the undercooling during solidification. The temperature change during solidification was measured by using the melting furnace shown in Fig. 1(b). The sample of $1.8 \times 10^{-2} \mathrm{~m}$ in outside diameter and $2.5 \times 10^{-2} \mathrm{~m}$ in height was inserted in an alumina crucible of $2.5 \times 10^{-2} \mathrm{~m}$ in outside diameter, $2.0 \times 10^{-2} \mathrm{~m}$ in inside diameter and $5.0 \times 10^{-2} \mathrm{~m}$ in height. It was thereafter heated to $1873 \mathrm{~K}$ under an argon gas atmosphere and then was maintained for $300 \mathrm{~s}$. After that, the degree of undercooling was measured under the cooling rates of $1.7 \times 10^{-1} \mathrm{Ks}^{-1}$ and $3.3 \times 10^{-1} \mathrm{Ks}^{-1}$. The degree of undercooling was defined as the difference between the liquidus temperature and the temperature which showed the maximum undercooling on the cooling curve. The temperature of sample was measured by using $\mathrm{R}$ type thermocouple of $3.0 \times 10^{-4} \mathrm{~m}$ in diameter put in an alumina tube of $3.0 \times 10^{-3} \mathrm{~m}$ in outside diameter and $2.0 \times 10^{-3} \mathrm{~m}$ in inside diameter. After the sample was melted, this alumina tube was immersed in the molten sample from the above and was fixed at $1.0 \times 10^{-2} \mathrm{~m}$ from bottom.

A trace amount of granular pure $\mathrm{Bi}$ was added into the molten steel as follows. It was pressed on the tip of pure iron

Table 1. Chemical composition (mass\%) and liquidus temperature of samples.

\begin{tabular}{ccccccc}
\hline sample & $\mathrm{C}$ & $\mathrm{Si}$ & $\mathrm{Mn}$ & $\mathrm{P}$ & $\mathrm{S}$ & liquidus temp. \\
\hline $\mathrm{A}$ & 0.05 & 0.20 & 1.4 & 0.006 & 0.002 & $1800 \mathrm{~K}$ \\
$\mathrm{~B}$ & 0.08 & 0.21 & 1.3 & 0.005 & 0.003 & $1796 \mathrm{~K}$ \\
$\mathrm{C}$ & 0.12 & 0.17 & 1.4 & 0.006 & 0.002 & $1793 \mathrm{~K}$ \\
$\mathrm{D}$ & 0.18 & 0.21 & 1.4 & 0.005 & 0.002 & $1790 \mathrm{~K}$ \\
$\mathrm{E}$ & 0.49 & 0.22 & 1.3 & 0.007 & 0.003 & $1764 \mathrm{~K}$ \\
$\mathrm{~F}$ & 0.62 & 0.20 & 1.4 & 0.008 & 0.003 & $1756 \mathrm{~K}$ \\
\hline
\end{tabular}


plate of $2.0 \times 10^{-2} \mathrm{~m}$ in length with the opposite side of this plate fixed by the alumina tube for temperature measurement. The tube was moved down to the molten steel sample. After that, it was held for $60 \mathrm{~s}$, followed by dipped in molten steel to measure the temperature during cooling.

The liquidus temperature was defined as the value which was extrapolated to cooling rate of $0 \mathrm{Ks}^{-1}$ based on the measured temperature which changed into the first derivation on the cooling curve to time at cooling rate of $1.7 \times 10^{-2}$, $1.7 \times 10^{-1}$ and $3.3 \times 10^{-1} \mathrm{Ks}^{-1}$. When the cooling rate was $1.7 \times 10^{-2}$, it was impossible to determine the degree of undercooling due to too small extent.

\section{Analytical Method}

\subsection{Dendritic Growth Model}

For the unidirectional solidification, under the constrained growth condition which are fixed by both the temperature gradient and the growth rate, the KGT model ${ }^{17)} \mathrm{can}$ be applied to analyze the experimental results. The undercooling at solid-liquid interface $\Delta T$ is obtained as a sum of the undercoolings due to solute diffusion $\Delta T_{C}$, the undercooling due to curvature by Gibbs-Thomson effect $\Delta T_{R}$ and the undercooling due to kinetics $\Delta T_{k}$. Moreover, the undercooling $\Delta T_{U}$ is generated by both the interaction between cells and the solute distribution ahead of cell tip under the unidirectional solidification condition. ${ }^{27)}$ In the present paper, these undercoolings were taken into consideration in analysis for the dendritic growth.

$$
\begin{array}{r}
\Delta T=\Delta T_{C}+\Delta T_{R}+\Delta T_{k}+\Delta T_{U} \\
\Delta T_{C}=\frac{k \Delta T_{0} I v(P)}{1-(1-k) I v(P)}=\sum_{i} m_{i}\left(C_{L, i}^{t i p}-C_{0, i}\right) \\
\Delta T_{R}=\frac{2 \Gamma}{r} \\
\Delta T_{k}=\frac{V}{\mu_{0}} \\
\Delta T_{U}=\frac{G D}{V}
\end{array}
$$

where, $k$ : equilibrium partition coefficient $(-), T_{0}$ : equilibrium solidification range $(\mathrm{K}), r$ : dendrite tip radius $(\mathrm{m}), V$ : growth rate $\left(\mathrm{ms}^{-1}\right), G$ : temperature gradient in liquid $\left(\mathrm{Km}^{-1}\right)$, $D$ : diffusion coefficient in liquid $\left(\mathrm{m}^{2} \mathrm{~s}^{-1}\right), \mu_{0}$ : linear kinematic coefficient $\left(=\mathrm{V}_{0} \mathrm{~V}_{\mathrm{m}} \Delta \mathrm{S} / \mathrm{RT}_{\mathrm{f}}\right)\left(\mathrm{ms}^{-1} \mathrm{~K}^{-1}\right), \Gamma$ : Gibbs-Thomson coefficient $(=\sigma / \Delta \mathrm{S})(\mathrm{Km}), \sigma$ : solid-liquid interface energy $\left(\mathrm{Jm}^{-2}\right), V_{0}$ : sound velocity $\left(\mathrm{ms}^{-1}\right), V_{\mathrm{m}}$ : molar volume $\left(\mathrm{m}^{3} \mathrm{~mol}^{-1}\right), \Delta \mathrm{S}$ : entropy of fusion per unit volume $\left(\mathrm{Jm}^{-3} \mathrm{~K}^{-1}\right)$, $T_{f}$ : melting point of pure iron $(\mathrm{K}), R$ : gas constant $(=8.31447)\left(\mathrm{Jmol}^{-1} \mathrm{~K}^{-1}\right), m_{i}$ : liquidus slope of element $i$ $\left(\mathrm{K} \cdot \operatorname{mass} \%^{-1}\right), C_{L, i}^{t i p}$ : concentration of element $i$ in liquid at dendrite tip (mass\%), $C_{0, i}$ : initial concentration of element $i$ (mass\%), $I v$ : Ivantsov function.

According to the relationship described above, the dendrite tip temperature $\mathrm{T}^{\text {tip }}$ can be shown as follows. ${ }^{17,37-39)}$

$$
T^{t i p}=T_{m}+\sum_{i} m_{i}\left(C_{L, i}^{t i p}-C_{0, i}\right)-\frac{2 \Gamma}{r}-\frac{V}{\mu_{0}}-\frac{G D}{V} .
$$

Kurz et al. ${ }^{17)}$ have applied the marginal stability criterion to the dendrite growth theory of an alloy under unidirectional solidification condition and suggested the equation of maximum stable wave length $\lambda_{\mathrm{s}}$ of plane interface as a function of tip radius $r$.

$$
r=\lambda_{S}=\left[\frac{\Gamma}{\sigma^{*} \sum_{i}\left(m_{i} G_{C, i}-G\right)}\right]^{\frac{1}{2}}
$$

where, $G_{C, i}$ : concentration gradient of element $i\left(\operatorname{mass} \% \cdot \mathrm{m}^{-1}\right)$, $\sigma^{*}$ : stability constant.

The value of $\sigma^{*}$ was assumed two times $1 /\left(4 \pi^{2}\right)$, as the analysis of Oguchi et al. ${ }^{40)}$

Because a dendritic growth of alloy is governed by solute diffusion, it is assumed that the diffusion of solute in the solid can be neglected and the concentration at the interface is isoconcentration. Thereby the Ivantsov solution can be applied.

$$
C_{L, i}^{t i p}=\frac{C_{0, i}}{1-\left(1-k_{i}\right) \operatorname{Iv}(P)} .
$$

For this solution, the law of conservation of mass is obeyed at a dendrite tip.

$$
G_{C, i}=\frac{\left(k_{i}-1\right) V C_{L, i}^{t i p}}{D_{i}}
$$

From this, the radius of curvature at dendrite tip can be obtained as the smaller value according to the following equation.

$$
G \rho^{2}+2 r \sum_{i}\left[m_{i} P_{i}\left(1-k_{i}\right) C_{L, i}^{t i p}\right]+\frac{\Gamma}{2 \sigma^{*}}=0 \ldots \ldots .
$$

$\sigma$ has been obtained by a try and error method by the following manner. The value of $\lambda_{1}$ is found so as to agree with the measured value by substituting various $\sigma$ values for each sample by using the Eqs. (7) and (11) under the fixed condition of both $\mathrm{G}$ and $\mathrm{V}$.

\subsection{Heterogeneous Nucleation Model}

The solid-liquid interface energy can be predicted by using the equation of heterogeneous nucleation by Turnbull. ${ }^{22)}$

$$
\begin{aligned}
I=\frac{K}{\eta} \exp [ & {\left[-\frac{16 \pi}{3} \frac{\sigma^{3}}{k_{B} T\left(\Delta S \Delta T_{n}\right)^{2}} f(\theta)\right] \ldots \ldots . . } \\
\eta & =10^{-3.3} \exp \left(\frac{3.34 T_{m}}{T-T_{g}}\right) \\
f(\theta) & =\frac{1}{4}(2+\cos \theta)(1-\cos \theta)^{2}
\end{aligned}
$$

where, $I$ : heterogeneous nucleation rate $\left(\mathrm{m}^{-3} \mathrm{~s}^{-1}\right), K$ : kinematic term of nucleation $10^{39}\left(\mathrm{Nm}^{-5}\right), \eta$ : viscosity term $\left(\mathrm{Nsm}^{-2}\right), \Delta T_{n}$ : undercooling for nucleation $(\mathrm{K}), T_{m}$ : liquidus temperature (K), $T_{g}$ : glass transition temperature $\left(T_{m} \times 0.33\right)$ $(\mathrm{K}), f(\theta)$ : factor of contact angle, $k_{B}$ : Boltzmann constant $\left(=1.38 \times 10^{-23}\right)\left(\mathrm{JK}^{-1}\right)$.

To predict the solid-liquid interface energy based on the cooling curve obtained from the experiment, the heterogeneous nucleation temperature and the nucleation time were 
calculated by using the following equation.

$$
\int_{T_{n}}^{T_{m}} \frac{I}{\dot{T}} d T=n
$$

where, $T_{n}$ : temperature when maximum undercooling is shown $(\mathrm{K}), \dot{T}$ : cooling rate $\left(\mathrm{Ks}^{-1}\right), n$ : number of nucleus $\left(\mathrm{m}^{-3}\right)$. The population of primary dendrite arms was counted as $10^{6} \mathrm{~m}^{-2}$ near the tip of the thermocouple in the sample used for thermal analysis. When the primary dendrite arm is formed by one nucleus and grows in parallel mutually, the number of nuclei per unit volume is equal to the number of the primary dendrite arms per unit area. Though the contact angle between solid and liquid is unknown, it is possible to estimate by changing the cooling rates.

\subsection{Physical Properties}

The physical properties which were necessary for the analysis were calculated based on the recent thermodynamics data. To examine the influence of the primary phase, the sample was assumed to be a $\mathrm{Fe}-\mathrm{C}-1.4$ mass\%Mn ternary system with $\mathrm{C}$ concentration dealt as variable.

Figures 2(a)-2(f) show the physical properties obtained by the equilibrium thermodynamic calculation. ${ }^{45}$ )

Figure 2(a) shows the effect of $\mathrm{C}$ content on the liquidus slopes of $\mathrm{C}$ and $\mathrm{Mn}$. The liquidus slope varies depending on the primary phase for both cases of C and Mn. Obviously, the slope of $\delta$ phase is larger than that of $\gamma$ phase. The difference of slope of C between $\delta$ and $\gamma$ phases is larger than that of $\mathrm{Mn}$. It can be understood that the effect of $\mathrm{C}$ is more significant.

Figure 2(b) shows the effect of $\mathrm{C}$ content on the equilibrium partition coefficient of $\mathrm{C}$ and $\mathrm{Mn}$. The equilibrium partition coefficient of $\mathrm{C}$ varies with the $\mathrm{C}$ concentration; the value of the primary $\delta$ phase is smaller than that of the pri-
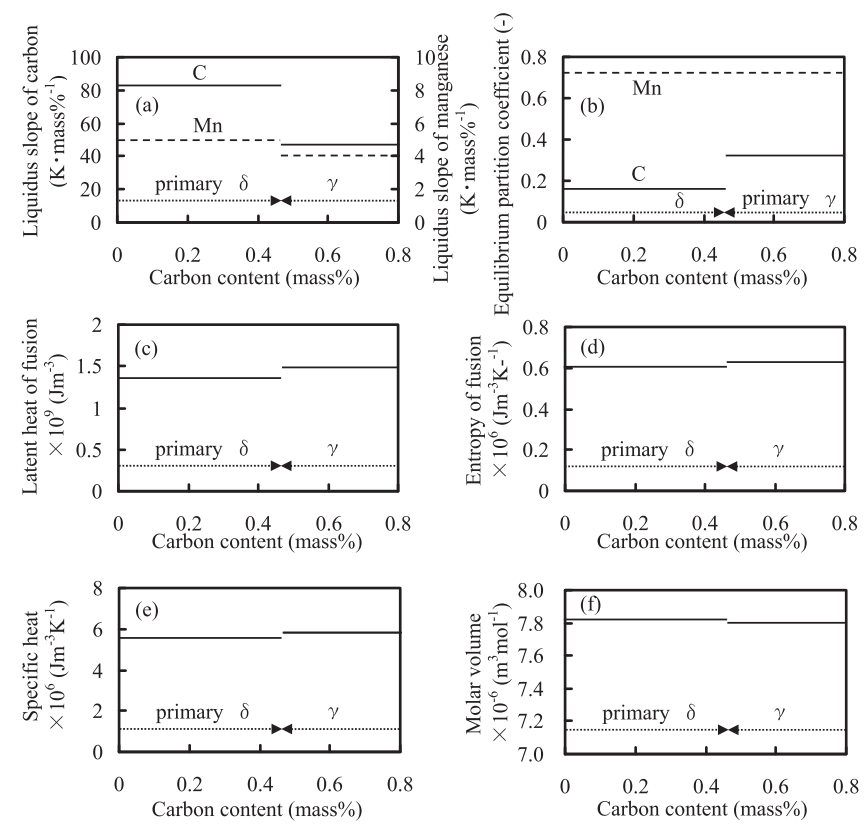

Fig. 2. Relationship between physical properties for dendrite growth model and $\mathrm{C}$ content for $\mathrm{Fe}-\mathrm{C}-1.4$ mass $\% \mathrm{Mn}$ steel sample. (a) liquidus slope of $\mathrm{C}$ and $\mathrm{Mn}$, (b) equilibrium partition coefficient, (c) latent heat of fusion, (d) entropy of fusion, (e) specific heat and (f) molar volume. mary $\gamma$ phase. When the primary phase is the same, the equilibrium partition coefficient of $\mathrm{C}$ takes constant value. The equilibrium partition coefficient of $\mathrm{Mn}$ is constant independent on $\mathrm{C}$ concentration.

Figures 2(c)-2(f) show the change of latent heat of fusion, entropy of fusion, specific heat and molar volume of alloy with $\mathrm{C}$ concentration. Though these values vary with the primary phase depending on $\mathrm{C}$ concentration, the difference is small.

The solid-liquid interface energy was evaluated by using these values (Table 2 and Fig. 2).

\section{Results and Discussion}

\subsection{Solidification Microstructure}

Figures 3(a)-3(f) show the solidification microstructures parallel to the growth direction near the solid-liquid interface and cross section perpendicular to the growth direction below $5.0 \times 10^{-4} \mathrm{~m}$ from solidification front. In order to evaluate the solid-liquid interface energy, it is necessary to observe the solidification microstructure which grows under steady state conditions. In this study, it was confirmed that the dendrite grew in a steady state when the heating unit was moved by distance of $1.5 \times 10^{-2} \mathrm{~m}$ or more. Because a primary dendrite arm on the solid side near the solid-liquid interface dose not grow after quench, it is possible to accurately estimate the solid-liquid interface energy by measuring the primary arm spacing. Moreover, according to the observation of the solidification microstructure perpendicular to the growth direction, it is obvious that the primary dendrite arms grow in a steady state due to the regular arrangement of dendrite arms.

Figure 4 shows the relationship between the primary dendrite arm spacing obtained from Eq.(1) and C concentration. In the primary $\delta$ phase region, the primary dendrite arm spacing increases with increasing $\mathrm{C}$ concentration. In the primary $\gamma$ phase region, the tendency is recognized to be the same. It is assumed that the primary dendrite arm spacing changes discontinuously at the $\mathrm{C}$ concentration of 0.45 mass $\%$ where primary phase alters. This tendency is consistent with a previous study. ${ }^{33)}$

Table 2. Physical properties for calculation.

\begin{tabular}{|c|c|c|c|}
\hline symbol & property & value & ref. \\
\hline$\kappa$ & thermal conductivity of liquid & $35\left(\mathrm{Wm}^{-1} \mathrm{~K}^{-1}\right)$ & 41) \\
\hline $\mathrm{D}_{\mathrm{C}}^{\mathrm{L}}$ & diffusivity of carbon in liquid & $8.4 \times 10^{-7}\left(\mathrm{~m}^{2} \mathrm{~s}^{-1}\right)$ & 42) \\
\hline $\mathrm{D}_{\mathrm{C}}{ }^{\delta}$ & diffusivity of carbon in $\delta$ phase & $\begin{array}{l}1.27 \times 10^{-6}(\exp -19450 / \mathrm{RT}) \\
\left(\mathrm{m}^{2} \mathrm{~s}^{-1}\right)\end{array}$ & 34) \\
\hline $\mathrm{D}_{\mathrm{C}}^{\gamma}$ & diffusivity of carbon in $\gamma$ phase & $\begin{array}{l}7.61 \times 10^{-6}(\exp -32160 / \mathrm{RT}) \\
\left(\mathrm{m}^{2} \mathrm{~s}^{-1}\right)\end{array}$ & 34) \\
\hline $\mathrm{D}_{\mathrm{Mn}}^{\mathrm{L}}$ & $\begin{array}{l}\text { diffusivity of manganese } \\
\text { in liquid }\end{array}$ & $4.4 \times 10^{-9}\left(\mathrm{~m}^{2} \mathrm{~s}^{-1}\right)$ & 42) \\
\hline $\mathrm{D}_{\mathrm{Mn}}^{\delta}$ & $\begin{array}{l}\text { diffusivity of manganese } \\
\text { in } \delta \text { phase }\end{array}$ & $\begin{array}{l}7.60 \times 10^{-5}(\exp -53640 / \mathrm{RT}) \\
\left(\mathrm{m}^{2} \mathrm{~s}^{-1}\right)\end{array}$ & 34) \\
\hline $\mathrm{D}_{\mathrm{Mn}}^{\gamma}$ & $\begin{array}{l}\text { diffusivity of manganese } \\
\text { in } \gamma \text { phase }\end{array}$ & $\begin{array}{l}5.50 \times 10^{-6}(\exp -59600 / \mathrm{RT}) \\
\left(\mathrm{m}^{2} \mathrm{~s}^{-1}\right)\end{array}$ & 34) \\
\hline $\mathrm{a}_{0}$ & interatomic distance in liquid & $1.0 \times 10^{-9}(\mathrm{~m})$ & 43) \\
\hline $\mathrm{V}_{0}$ & sound velocity in liquid & $1.5 \times 10^{3}\left(\mathrm{~ms}^{-1}\right)$ & 44) \\
\hline $\mathrm{T}_{\mathrm{f}}$ & melting point of pure iron & $1811(\mathrm{~K})$ & 41) \\
\hline
\end{tabular}




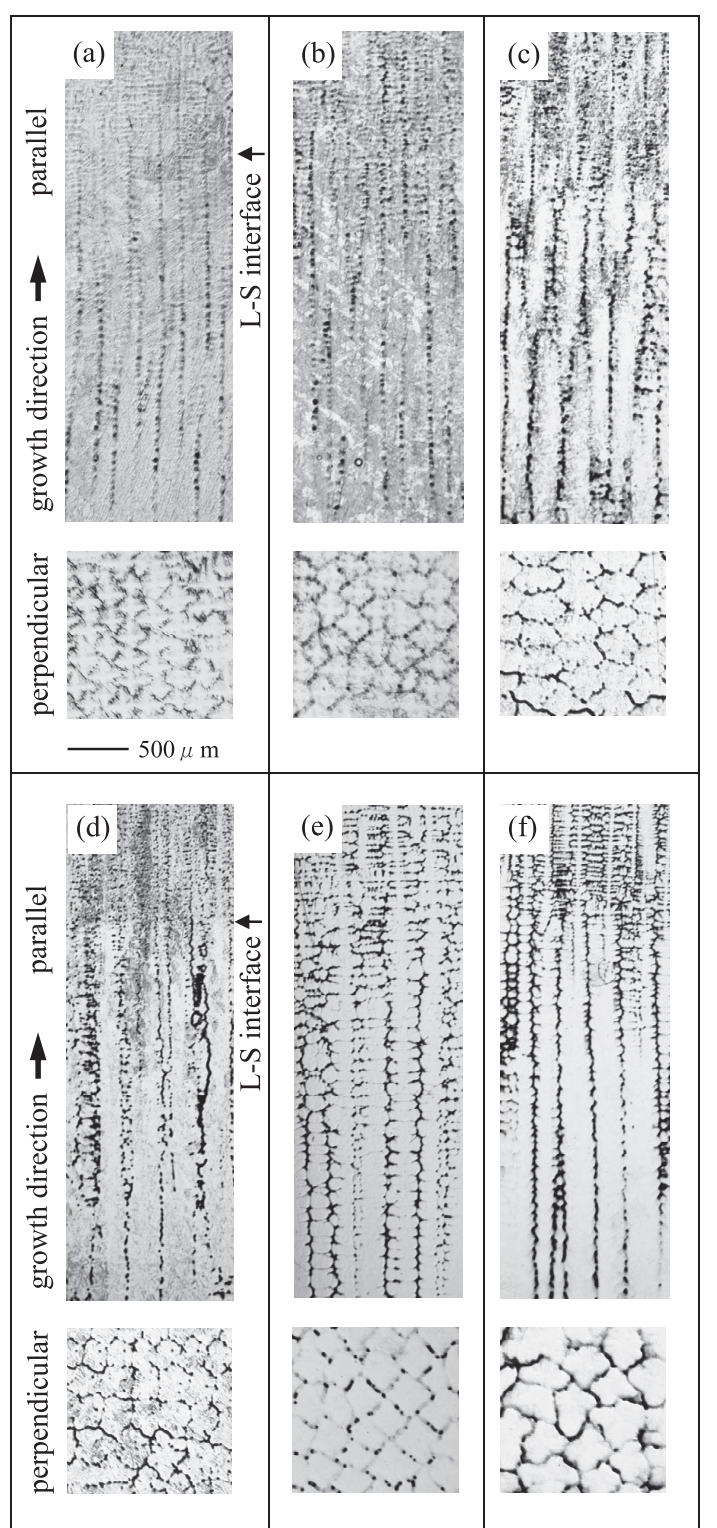

Fig. 3. Unidirectional solidification microstructure paralleled to growth direction and perpendicular to growth direction below $5.0 \times 10^{-4} \mathrm{~m}$ from solid-liquid interface. (a) sample A, (b) B, (c) C, (d) D, (e) E and (f) F.

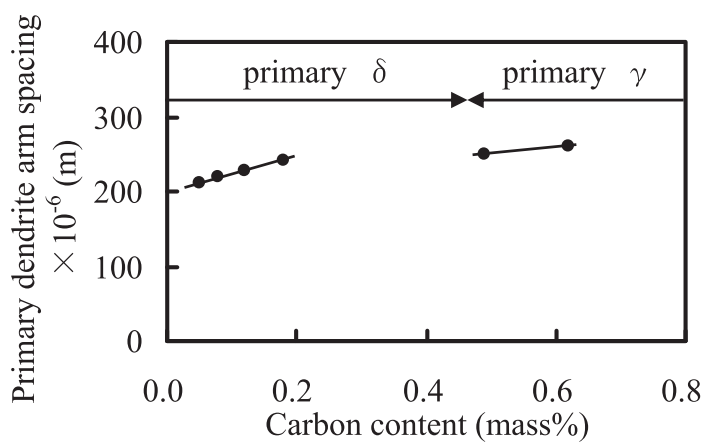

Fig. 4. Relationship between primary dendrite arm spacing and $\mathrm{C}$ content.

\subsection{Calculation of the Solid-liquid Interface Energy}

\subsubsection{Unidirectional Solidification}

In this study, as mentioned above, the relationship between growth rate and primary dendrite arm spacing was
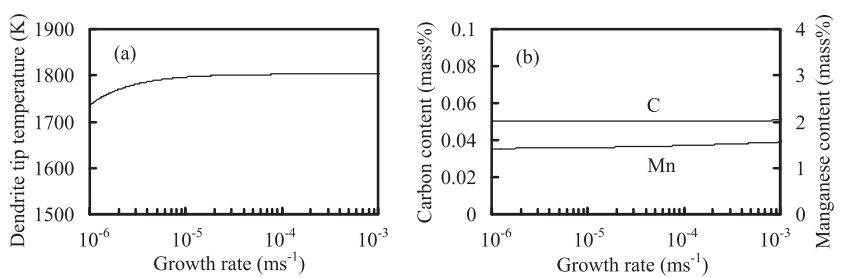

Fig. 5. Calculated relationship between (a) dendrite tip temperature, (b) $\mathrm{C}$ and $\mathrm{Mn}$ content at dendrite tip and growth rate by using dendrite growth model.

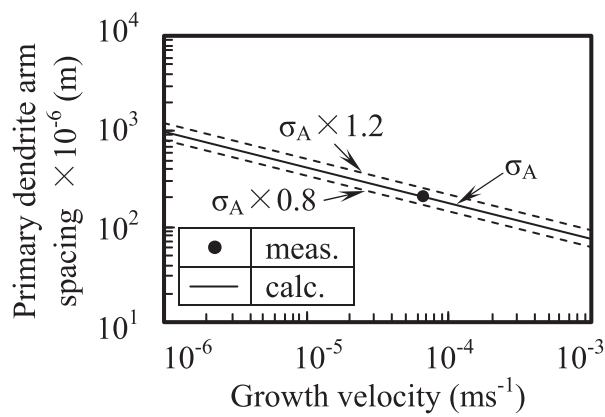

Fig. 6. Change in primary dendrite arm spacing with growth rate for unidirectional solidification of sample A. Solid circle represents the experimental result, and solid and dashed line represent the calculated results.

evaluated as a function of the solid-liquid interface energy by using the dendrite growth model. In order to evaluate the solid-liquid interface energy, it is necessary that both the temperature and the concentration of dendrite tip are kept in a steady state. Therefore, consideration was made on how temperature and concentration of dendrite tip, and growth rate of dendrite are related with each other.

Figure 5(a) shows the relationship between tip temperature and growth rate of dendrite for the case of which initial $\mathrm{C}$ concentration is 0.05 mass $\%$ and Mn concentration is 1.4 mass $\%$. At a lower growth rate, the dendrite tip temperature increases with the growth rate, while the dendrite tip temperature is constant in this experimental range. It is understood that the dendrite grows in a steady state.

Figure 5(b) shows the change of $\mathrm{C}$ and $\mathrm{Mn}$ concentration at dendrite tip with growth rate for the case of initial $\mathrm{C}$ concentration 0.05 mass\%. It can be seen that the concentrations of both $\mathrm{C}$ and $\mathrm{Mn}$ slightly increase with increasing growth rate. Then it is able to be assumed that the concentrations of $\mathrm{C}$ and $\mathrm{Mn}$ at dendrite tip are constant. Therefore, the number of dendrites in the sample was large enough and the change of both temperature and concentration near the solid-liquid interface were compensated. It is considered that the influence of experimental error is small to evaluate the solid-liquid interface energy.

Figure 6 shows the relationship between primary dendrite arm spacing and growth rate varying with the solid-liquid interface energy. The primary dendrite arm spacing decreases with increasing growth rate. The primary dendrite arm spacing changes with growth rate depending on the solidliquid interface energy. Comparing at the same growth rate, the primary dendrite arm spacing decreases with decreasing the solid-liquid interface energy. The relationship between primary dendrite arm spacing and growth rate in agreement 
with the experimental result gives the solid-liquid interface energy. The solid line passes through the measured value while dashed lines show the range of $\pm 20 \%$. The primary dendrite arm spacing increased with increasing the solidliquid interface energy. Likewise, the solid-liquid interface energy can be evaluated for the sample B-F.

Figure 7 shows the solid-liquid interface energy plotted against $\mathrm{C}$ concentration. In either primary phase, the solidliquid interface energy decreases with increasing $\mathrm{C}$ concentration. However, the change of solid-liquid interface energy with $\mathrm{C}$ concentration in the $\delta$ phase is different from that of the $\gamma$ phase. It is considered that the value changes discontinuously at the $\mathrm{C}$ concentration of boundary between $\delta$ and $\gamma$ phases. As shown in Fig. 4, it was similar behavior to a discontinuous change of the primary dendrite arm spacing. The value of pure iron ${ }^{22)}$ plotted in this figure agrees to the extrapolated value of the primary $\delta$ phase. The primary dendrite arm spacing may change depending on the solid-liquid interface energy.

\subsubsection{Cooling Curve}

Figure 8(a) shows the cooling curve of the sample of $\mathrm{C}$ concentration of 0.12 mass $\%$ and $\mathrm{Mn}$ concentration of 1.4 mass \%. In general, solidification starts below the liquidus temperature with a constant cooling rate showing the degree of maximum undercooling. Then, the temperature shows the maximum recalescence temperature followed by a decrease again. The solid-liquid interface energy was calculated by using the Eqs. (12)-(15) based on the degree of maximum undercooling. It is considered that heterogeneous nucleation takes place on the surface of alumina tube for protection of thermocouple. A contact angle in the equation of heterogeneous nucleation was estimated based on the measurement results of undercooling with different cooling

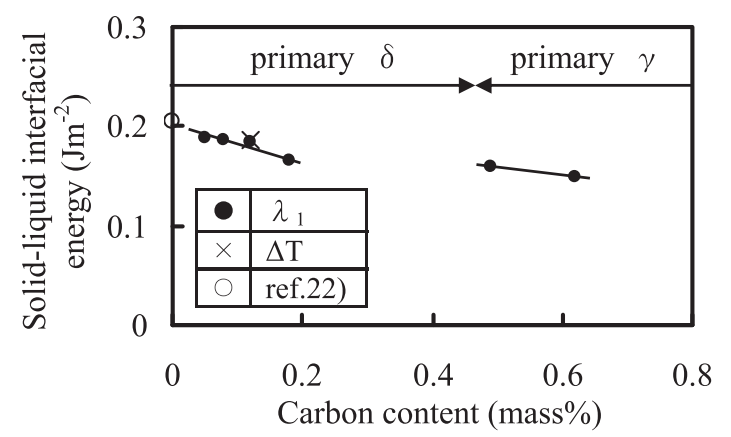

Fig. 7. Relationship between solid-liquid interfacial energy and $\mathrm{C}$ content. $\lambda_{1}$ means the experimental results for unidirectional solidification and $\Delta \mathrm{T}$ means the experimental result for temperature measurement.
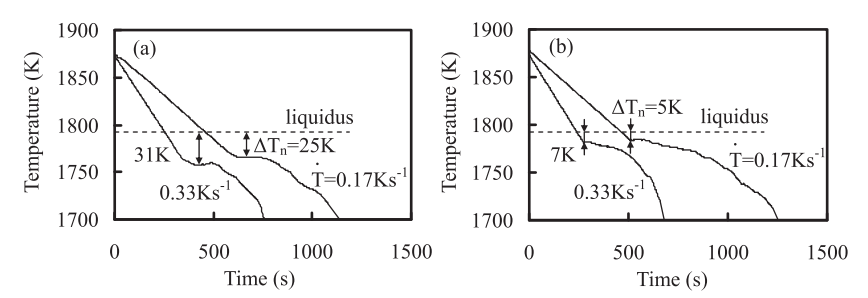

Fig. 8. Measured cooling curve of $\mathrm{Fe}-0.12$ mass $\% \mathrm{C}-1.4$ mass $\% \mathrm{Mn}$ steel samples. (a) without $\mathrm{Bi}$ and (b) with 30 ppm Bi. rates.

Figure 9 shows the relationship between degree of undercooling and nucleation time which is based on the equation of heterogeneous nucleation as a function of contact angle. The contact angle $\theta$ was estimated so as to agree to the curve by substituting various contact angles. The open circle shows the result which is $33^{\circ}$. Using this value and Eqs. (12)-(15), the solid-liquid interface energy can be obtained.

This value was plotted in Fig. 7 shown as a cross mark, in which the values by unidirectional solidification have been indicated. The value by undercooling is found to well agree with the line obtained from the primary dendrite arm spacings by unidirectional solidification. Consequently, it can be said that the both experimental methods are accurate enough to evaluate the solid-liquid interface energy.

\subsection{Refinement of Solidification Microstructure by Decreasing Solid-liquid Interfacial Energy}

A general way to control solidification microstructure is to vary solidification conditions. Alternatively, one can accomplish it by varying the solid-liquid interface energy. Addition of $\mathrm{Bi}$ as an interfacial active agent is able to decrease the solid-liquid interface energy. Then the analysis has been done by both the dendrite growth and the heterogeneous nucleation models. In the experiment, $\mathrm{Bi}$ was added to the sample of 0.12 mass $\% \mathrm{C}$ and 1.4 mass $\% \mathrm{Mn}$.

\subsubsection{Unidirectional Solidification}

Figure 10 shows the solidification microstructure of the sample varying $\mathrm{Bi}$ concentration under the unidirectional solidification condition. The pictures are solidification microstructures of the longitudinal cross sections near the solid-liquid interface along with the transverse cross sections below $5.0 \times 10^{-4} \mathrm{~m}$ from solidification front. It is understood that addition of $\mathrm{Bi}$ does not affect the morphology of solidification microstructure of dendrite. The higher the Bi concentration is, the finer the dendrite is. Moreover, it was confirmed that the primary dendrite arms grew in a steady state condition, because the primary dendrite arms were arranged regularly. The primary dendrite arm spacing was calculated by using the Eq. (1).

Figure 11 shows the change of primary dendrite arm spacing with Bi concentration. A trace amount of Bi significantly affects the primary dendrite arm spacing. Apparently, the higher $\mathrm{Bi}$ concentration is, the finer the primary dendrite arm spacing is.

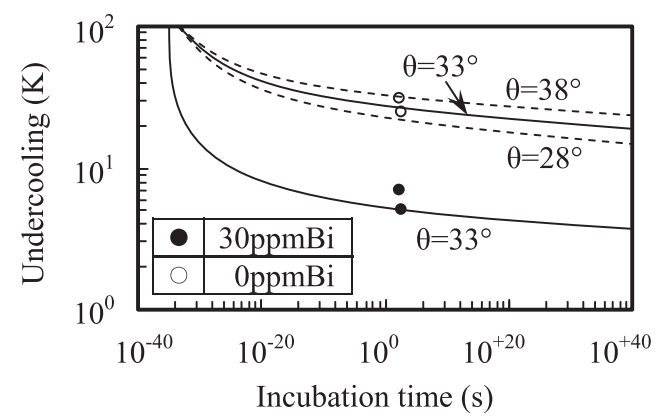

Fig. 9. Calculated relationship between undercooling for heterogeneous nucleation and incubation time. $\theta$ means the contact angle for heterogeneous nucleation. 


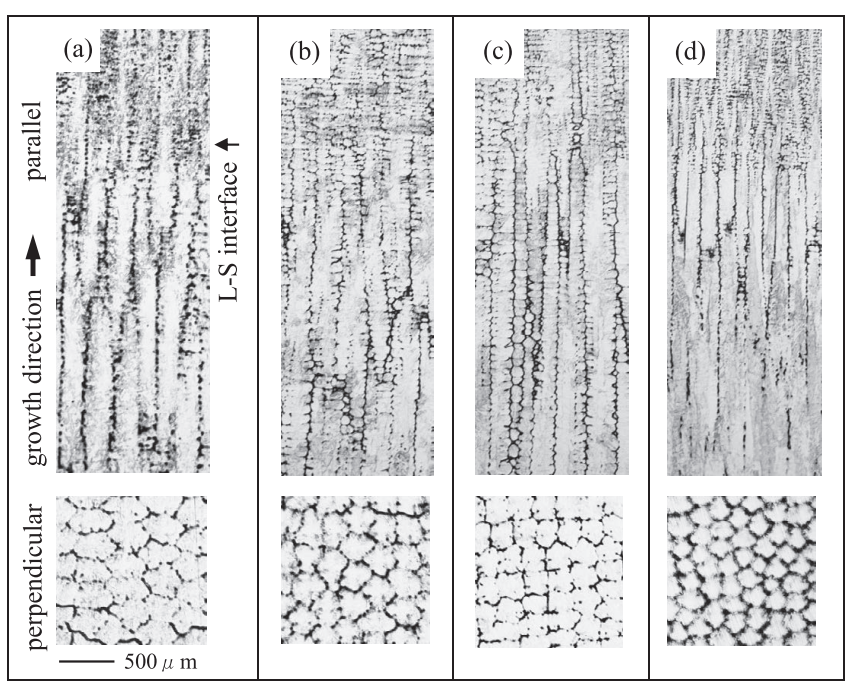

Fig. 10. Unidirectional solidification microstructure paralleled to growth direction and perpendicular to growth direction below $5.0 \times 10^{-4} \mathrm{~m}$ from solid-liquid interface. (a) Bi content was $0 \mathrm{ppm}$, (b) $11 \mathrm{ppm}$, (c) $25 \mathrm{ppm}$ and (d) $31 \mathrm{ppm}$.

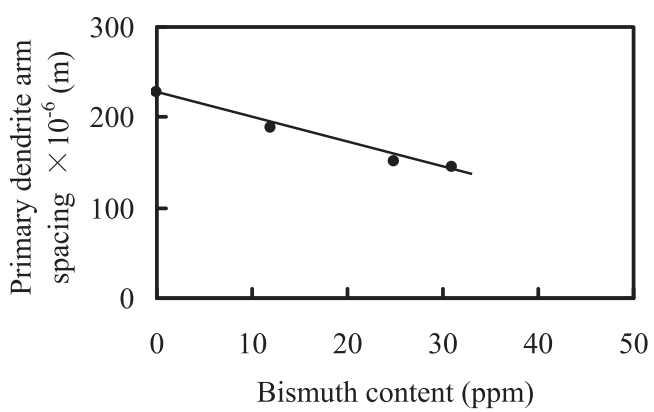

Fig. 11. Relationship between primary dendrite arm spacing and Bi content.

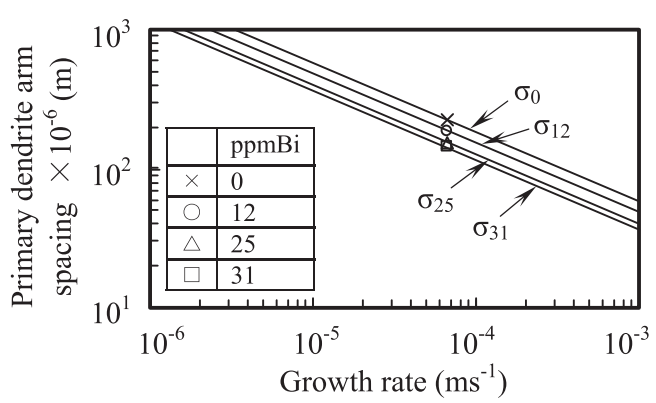

Fig. 12. Change in primary dendrite arm spacing with growth rate under various solid-liquid interfacial energy with $\mathrm{Bi}$.

Figure 12 shows the relationship between primary dendrite arm spacing and growth rate by using the dendrite growth model. The primary dendrite arm spacing decreases with increasing $\mathrm{Bi}$ concentration. Solid-liquid interface energy can be estimated by fitting this figure so as to agree with the measurement values resulting in the evaluation of solid-liquid interface energy, quantitatively.

Figure 13 shows the solid-liquid interface energies as a function of $\mathrm{Bi}$ concentration. Within the experimental conditions, the solid-liquid interface energy decreases with increasing Bi concentration. As recognized in Figs. 11 and 13 , it was clarified that the primary dendrite arm spacing was able to be smaller by a decrease of solid-liquid interface

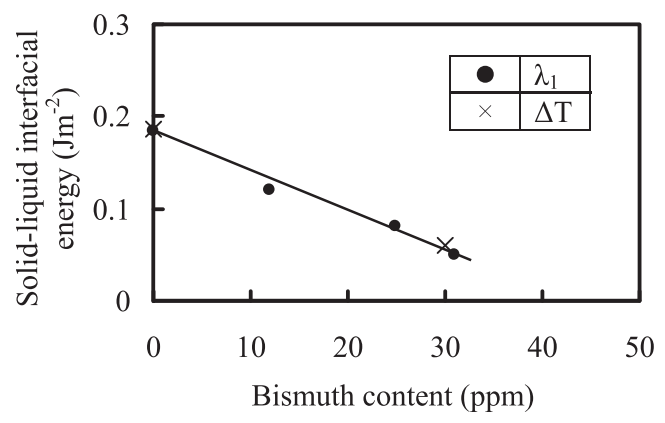

Fig. 13. Relationship between solid-liquid interfacial energy and Bi content. $\lambda_{1}$ means the experimental results for unidirectional solidification and $\Delta \mathrm{T}$ means the experimental result for temperature measurement.

energy by the addition of a trace amount of $\mathrm{Bi}$.

\subsubsection{Cooling Curve}

Figure 8(b) shows the cooling curve of the samples of $30 \mathrm{ppm} \mathrm{Bi}$. The influence of $\mathrm{Bi}$ addition on cooling curve is clarified by comparing with that of $\mathrm{Bi}$ free as shown in Fig. 8(a). The cooling curve of (b) $30 \mathrm{ppm} \mathrm{Bi}$ is similar to (a) $\mathrm{Bi}$ free. It can be realized that the undercooling is smaller with $30 \mathrm{ppm} \mathrm{Bi}$. This result implies that the heterogeneous nucleation occurs easily owing to the smaller undercooling.

Figure 9 shows the relationship between undercooling and incubation time for heterogeneous nucleation. The contact angle $33^{\circ}$, obtained earlier with the Bi free sample, was applied for the case of $30 \mathrm{ppm} \mathrm{Bi}$. The solid-liquid interface energy can be calculated in the manner described above. These results shown in Fig. 13 have proved that the values from two experimental techniques agree with each other. Besides, predicted value in this study is valid.

To make the solidification microstructure finer, the intensive cooling in the secondary cooling zone has been adopted by the general technique for continuous casting process. In this study, it was shown that the solidification microstructure could be fine by decreasing the solid-liquid interface energy by addition of a trace amount of $\mathrm{Bi}$.

\subsection{Effect of Refinement of Dendrite}

A lot of studies ${ }^{46,47)}$ have been done on the improvement of mechanical properties of the steel products made from the ingots in which the solidification microstructure is refined and microsegregation is reduced. The primary dendrite arm spacings, governing the behavior of microsegregation, characterizes the solidification microstructure indicating the characteristic length for microsegregation.

In this study, it was shown that the primary dendrite arm spacing varied the solid-liquid interface energy during solidification depending on $\mathrm{C}$ concentration. Moreover, it was clarified that the primary dendrite arm spacing became smaller by adding a trace amount of $\mathrm{Bi}$. Then, to determine the influence of finer primary dendrite arm spacing on microsegregation, the behavior of microsegregation was analyzed by using the solute redistribution model ${ }^{48)}$ during and after solidification. ${ }^{48}$

Figures 14(a), 14(b) show the distribution of Mn concentration with distance from the center of dendrite during solidification for the arm spacings of $2.0 \times 10^{-6} \mathrm{~m}$ and $1.5 \times 10^{-6} \mathrm{~m}$ (as $75 \%$ of $2.0 \times 10^{-6} \mathrm{~m}$ ), respectively. To exam- 

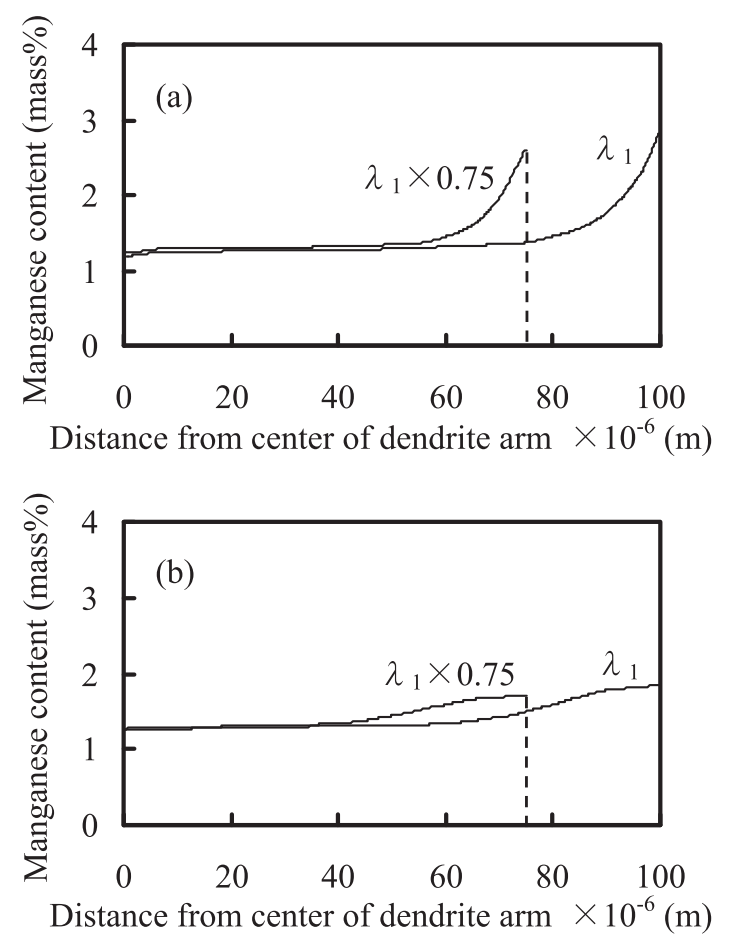

Fig. 14. Calculated results for relationship between Mn content and distance from center of dendrite arm. (a) just after solidification and (b) maintained for $7.2 \times 10^{2} \mathrm{~s}$ at $1473 \mathrm{~K}$ after solidification.

ine the change of the Mn concentration with time, the calculated results are shown just after solidification and after solidification maintained for $7.2 \times 10^{2} \mathrm{~s}$ at $1473 \mathrm{~K}$. The region of analysis was one half of a primary dendrite arm under symmetry assumption. The diffusion coefficients used for the analysis are shown in Table 2 .

The Mn concentration just after solidification showed the highest value in the interdendritic region and the minimum value shown in the core of dendrite by the solute redistribution. Mn concentration in the interdendritic region shows that the concentration in the case of arm spacing of $1.5 \times 10^{-6} \mathrm{~m}$ is smaller.

The effect of soaking at $1473 \mathrm{~K}$ after solidified is clear; the concentration of $\mathrm{Mn}$ in the interdendritic region became lower than that just after solidification. This is because Mn diffuses from the interdendritic region to the core region of dendrite. In this way, the smaller primary dendrite arm spacing can bring a quicker decrease in Mn content leading to uniform distribution.

Figure 15 shows the relationship between segregation ratio of $\mathrm{Mn}$ and primary dendrite arm spacing just after solidification. The segregation ratio of $\mathrm{Mn}$ is defined as the maximum concentration in the interdendritic region just after solidification divided by the initial concentration. The segregation ratio decreases with decreasing the dendrite arm spacing. It is effective to decrease the primary dendrite arm spacing for the decrease in the segregation ratio.

The larger Fourier number $\left(\mathrm{Fr}=\mathrm{D} \times \mathrm{t} / \mathrm{L}^{2}\right)^{49)}$ shows that the solute element is subject to diffuse where, D: diffusion coefficient, t: time, L: characteristic length. Accounting for microsegregation, the characteristic lengths $\mathrm{L}$ of Fourier number is equivalent to the primary dendrite arm spacing. Because the Fourier number is inversely proportional to the

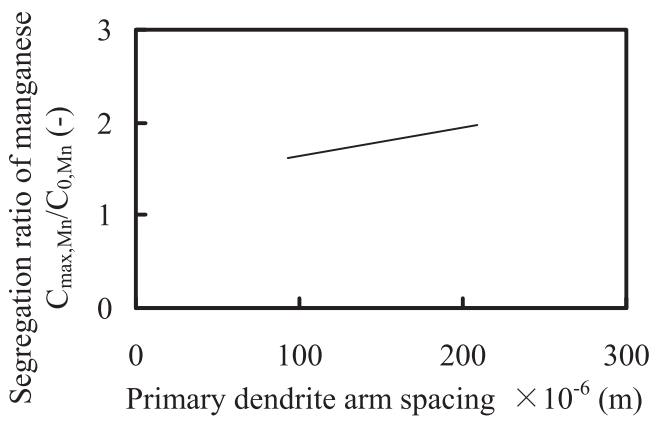

Fig. 15. Relationship between segregation ratio of Mn and primary dendrite arm spacing just after solidification.

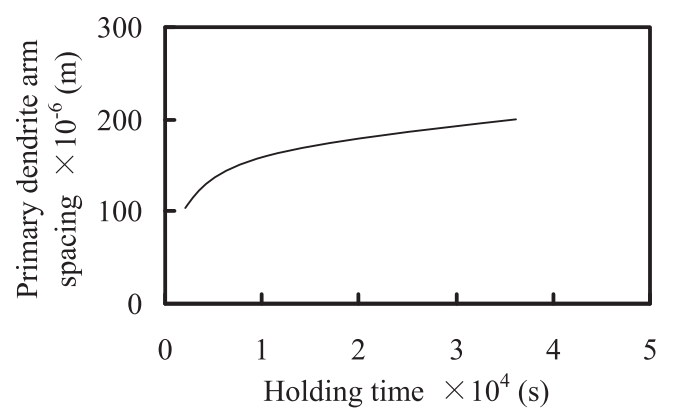

Fig. 16. Calculated result for the relationship between primary dendrite arm spacing and holding time at $1473 \mathrm{~K}$ under constant segregation ratio of $\mathrm{Mn}$ at 1.2 condition.

square of the primary dendrite arm spacing, it is effective to have primary dendrite arm spacing smaller. The technique to take time or increase temperature has been applied to have higher Fourier number.

To clarify the effect of diffusion after solidification with the smaller primary dendrite arm spacing, the condition to have 1.2 in segregation ratio of $\mathrm{Mn}$ at $1473 \mathrm{~K}$ is given in Fig. 16. The condition is shown as the curve in this figure. The smaller primary dendrite arm spacing can significantly save time required for diffusion. This is more effective for the condition of longer time.

\subsection{Secondary Dendrite Arm Spacing}

It was confirmed that the primary dendrite arm spacing became shorter by decreasing the solid-liquid interface energy in both the experiment and the theoretical analysis. The influence of the solid-liquid interface energy on the secondary dendrite arm spacing was determined as well as the primary dendrite arm spacing. The secondary dendrite arm spacing can be predicted by using the coarsening theory and it has been clarified that the arm spacing is proportion to a third of the power of partial solidification time. ${ }^{50)}$ The same partial solidification times are required to compare the secondary arm spacing. The arm spacing was therefore measured at the position which corresponds to the solidus temperature.

It is understood that the secondary dendrite arm spacing decreases with increasing Bi concentration as shown in Fig. 17. As can be understood in Fig. 13, the solid-liquid interface energy decreases by $\mathrm{Bi}$ addition.

Figure 18 shows that there is proportional relation between primary and secondary arm spacings of dendrite. The primary dendrite arm spacing decreases with increasing 


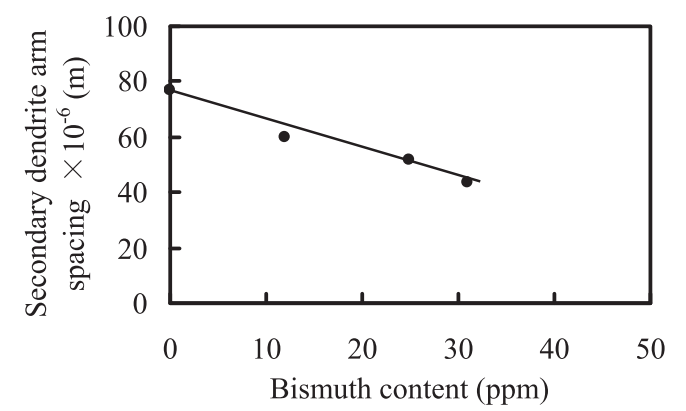

Fig. 17. Relationship between primary dendrite arm spacing just after solidification and $\mathrm{Bi}$ content.

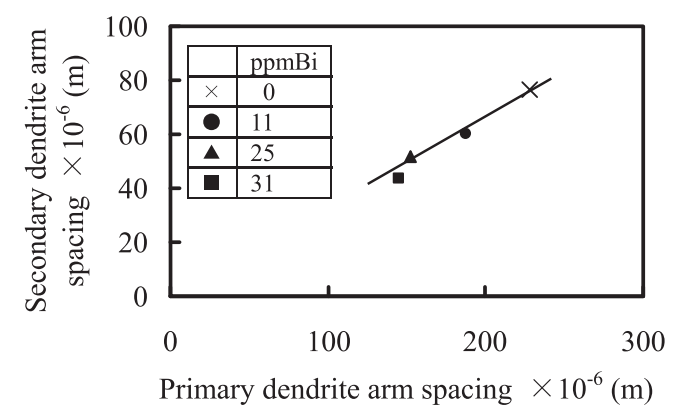

Fig. 18. Relationship between secondary dendrite arm spacing and primary dendrite arm spacing just after solidification.

Bi concentration. The secondary dendrite arm spacing decreases with increasing Bi concentration or alternatively decreasing the primary dendrite arm spacing.

As mentioned above, the both primary and secondary dendrite arm spacings become smaller with the lower solidliquid interface energy. An experiment was made to add a trace amount of $\mathrm{Bi}$ in molten steel for actual operation based on this result of fundamental experiment. Clearly, the primary dendrite arm spacings in the continuously cast slabs became smaller. Addition of a trace amount of $\mathrm{Bi}$ will be a new technology to lower the solid-liquid interface energy to control solidification microstructure. This is expected to fulfill the demands of high performance products for carbon steel in the future. Moreover, it is expected to apply this technology for high speed continuous casting, and the continuous casting steels that are difficult to cast.

\section{Conclusions}

Control of the dendritic growth which determines the size and the morphology of solidification microstructure in continuously cast slabs becomes important for demand of high performance products. A guideline of control of the dendritic growth can be obtained by the establishment of dendrite growth model and the progress of the prediction approach for solidification microstructure such as phase field model. However, to accurately simulate the dendritic growth, accurate physical properties are required. The solid-liquid interfacial energy has not been evaluated sufficiently due to difficulty to measure this value at high temperatures. In the present paper, the solid-liquid interface energy was estimated from the measurement results of both primary dendrite arm spacing by the unidirectional solidification and undercooling by the thermal analysis. For the refinement of den- dritic microstructure which was the final purpose in this paper, a trace amount of surface acting element $\mathrm{Bi}$ was added to molten steel samples to examine its effect. From these results, the following conclusions were obtained.

(1) The relationship between primary dendrite arm spacing and $\mathrm{C}$ concentration was varied with the primary phase which was either $\delta$ phase or $\gamma$ phase during solidification, and that relation was altered discontinuously at the boundary of these phases. When the primary phase was the same, the primary dendrite arm spacing increased with increasing $\mathrm{C}$ concentration.

(2) The solid-liquid interface energy of $\delta$ phase was different from that of $\gamma$ phase, and the value of $\delta$ phase was larger than that of $\gamma$ phase. The solid-liquid interface energy altered discontinuously at the boundary between these phases. It was similar behavior to a discontinuous change of the primary dendrite arm spacing. In either primary phase, the solid-liquid interfacial energy decreased with increasing $\mathrm{C}$ concentration.

(3) The solid-liquid interface energy decreased by addition of $30 \mathrm{ppm} \mathrm{Bi}$ and the primary dendrite arm spacing became smaller by about $25 \%$. Moreover, the undercooling became smaller with $30 \mathrm{ppm}$ Bi during solidification owing to the effect of decreasing the primary arm spacing.

(4) A decrease in the primary dendrite arm spacing improved microsegregation just after solidification. The smaller primary dendrite arm spacing could save time required for diffusion after solidification. It was effective to decrease the primary dendrite arm spacing for homogenization of the solute elements in the continuously cast slabs.

(5) The secondary arm spacing decreased with decreasing the primary dendrite arm spacing. The refinement of the secondary dendrite arm spacing was made possible by the addition of a trace amount of $\mathrm{Bi}$. It could be explained that one could uniformly refine the both primary and secondary dendrite arm spacings, which were basic sizes of solidification microstructure, by altering the solid-liquid interface energy.

\section{REFERENCES}

1) T. Maki: CAMP-ISIJ, 13 (2000), 730.

2) C. Ouchi: CAMP-ISIJ, 13 (2000), 750

3) S. Mizoguchi: Progress in Metallurgy for Ultra Refinement of Grain Size - Advanced Technology for Future Development in New Application of Steel, ISIJ, Tokyo, (2002), 53.

4) N. Fujita, T. Narushima, Y. Iguchi and C. Ouchi: ISIJ Int., 43 (2003), 1063.

5) Y. Sugitani, M. Nakamura and T. Watanabe: Tetsu-to-Hagané, 67 (1981), 1508.

6) T. Matsumiya, T. Saeki, J. Tanaka and T. Ariyoshi: Tetsu-to-Hagané, 68 (1982), 1782.

7) H. Esaka, T. Shirakami, T. Mizoguchi and S. Ogibayashi: Tetsu-toHagané, 81 (1995), 631.

8) H. Todoroki, R. Lertarom, T. Suzuki and A. W. Cramb: Steelmaking Conf. Proc., ISS, Warrendale, PA, (1997), 667.

9) H. Yamamura, K. Sasai, Y. Ueshima and Y. Mizukami: Tetsu-toHagané, 89 (2003), 645.

10) S. Dong, E. Niyama and K. Anzai: ISIJ Int., 35 (1995), 730.

11) H. Mizukami and A. Yamanaka: Tetsu-to-Hagané, 94 (2008), 507.

12) K. Miyazawa and K. Schwerdtfeger: Arch. Eisenhütenwes, 52 (1981), 413.

13) I. Onaka and T. Shimazu: Proc. 6th Int. Iron and Steel Cong., ISIJ, Tokyo, (1990), 681.

14) S. Ogibayashi, Y. Nishihara and T. Sato: Tetsu-to-Hagané, 83 (1997), 36.

15) T. Kajitani, J. M. Drezet and M. Rappaz: Metall. Mater. Trans., 32A (2001), 1479.

16) Y. Miyata and T. Suzuki: ISIJ Int., 26 (1986), 1002.

17) W. Kurz, B. Giovanola and R. Trivedi: Acta Metall., 34 (1986), 823. 
18) J. Lipton, W. Kurz and R. Trivedi: Acta Metall., 35 (1987), 975.

19) A. Karma: Phys. Rev. E, 49 (1994), 2245.

20) J. Tiaden, B. Nestler, H. J. Diepers and I. Steinbach: Physica D, 115 (1998), 73.

21) S. G. Kim, W. T. Kim and T. Suzuki: Phys. Rev. E, 60 (1999), 7186

22) D. Turnbull: J. App. Phys., 21 (1950), 1022.

23) R. H. Ewing: J. Cryst. Growth, 11 (1971), 221

24) T. Ohashi and W. A. Fisher: Tetsu-to-Hagané, 61 (1975), 3077.

25) O. Haida and T. Emi: Tetsu-to-Hagané, 63 (1977), 1564.

26) N. Eustathopoula: Int. Met. Rev., 28 (1983), 189.

27) M. H. Burden and J. D. Hunt: J. Cryst. Growth, 22 (1974), 109.

28) H. Jacobi and K. Schwerdtfeger: Metall. Trans., 7A (1976), 811.

29) T. Edvardsson, H. Fredriksson and I. Svensson: Mater. Sci., 10 (1976), 298.

30) K. Kishitake and T. Okamoto: Tetsu-to-Hagané, 63 (1977), 425.

31) I. Bessho, Y. Nagaoka and A. Suzuki: Tetsu-to-Hagané, 63 (1975), 1972.

32) M. A. Taha, H. Jacobi, M. Imagumbai and K. Schwerdtfeger: Metall. Trans., 13A (1982), 2131.

33) M. Suzuki, Y. Kitagawa and S. Miyahara: Tetsu-to-Hagané, 71 (1985), S1034.

34) Y. Ueshima, S. Mizoguchi, T. Matsumiya and H. Kajioka: Metall. Trans., 17B (1986), 845

35) K. Shin, T. Suzuki and T. Umeda: Tetsu-to-Hagané, 78 (1992), 275.
36) H. Esaka and S. Ogibayashi: Tetsu-to-Hagané, 84 (1988), 49

37) M. Bobadilla, J. Lacaze and G. Lesoult: J. Cryst. Growth, 89 (1988), 531.

38) T. Koseki and M. C. Flemings: ISIJ Int., 35 (1995), 611.

39) M. Rappaz and W. J. Boettinger: Acta Mater., 47 (1999), 3205.

40) K. Oguchi and T. Suzuki: ISIJ Int., 47 (2007), 1432.

41) W. Kurz and D. J. Fisher: Fundamentals of Solidification, Trans Tech Pub., Switzerland, (1998), 293.

42) Handbook of Physico-Chemical Properties at High Temperature, ISIJ, Tokyo, (1988), 181

43) W. J. Boettinger, S. R. Corriel and R. F. Sekerka: Mater. Sci. Eng., 65 (1984), 27

44) O. J. Kleppa: J Chem Phys, 18 (1950), 1331.

45) B. Jansson, M. Schalin, M. Selleby and B. Sundman: Computer Software in Chemical and Extractive Metallurgy, ed. by C. W. Bale and G. A. Iron, The Met. Soc. of CIM, Quebec, (1993), 57.

46) R. A. Grange: Metall. Trans., 2 (1971), 417.

47) G. Krauss: Iron Steel Technol., 1 (2004), 145.

48) H. Mizukami, A. Yamanaka and T. Watanabe: ISIJ Int., 42 (2002), 964.

49) M. E. Glicksman: Principle of Solidification, Springer, New York, (2011), 118.

50) T. Z. Kattamis and M. C. Flemings: Trans. Met. Soc. AIME, 233 (1965), 992. 